\title{
The Electrical Characteristics of Power FET using Super Junction for Advance Power Modules
}

\author{
Ey Goo Kang**
}

\begin{abstract}
The maximum breakdown voltage's characteristic within the Super Junction MOSFET structure comes from $\mathrm{N}$-Drift and P-Pillar's charge balance. By developing P-Pillar from Planar MOSFET, it was confirmed that the breakdown voltage is improved through charge balance, and by setting the gate voltage at 10V, the characteristic comparisons of Planar MOSFET and Super Junction MOSFET are shown in picture 6. The results show that it had the same breakdown voltage as Planar MOSFET which increased temperature resistance by $87.4 \%$ at $.019 \Omega \mathrm{cm}^{2}$ which shows that by the temperature resistance increasing, the power module's power dissipation improved.
\end{abstract}

Key words: Planar, Super Juction, MOSFET, Charge balance, Pillar, Deep Trench

\section{Introduction}

Worldwide, environmentally-friendly technology is a mantra, and power to lead the industry in the future is seen as a trend. The term "green" began in order to prevent global warming by reducing carbon emissions which has been continually developed by most of the industry. As a result, the car manufacturers are also competing for environment-friendly automobiles development and release, and there is rapid growth of the electric automobile's.[1-2]

engine's main component: the battery and charger. The electric car battery charger DC - DC Power Converter device for the $600 \mathrm{~V} / 20$ A Power MOSFET level must be used, however, the existing Power MOSFET is hard to use due to resistance from high-driven loss. To this end, compared to existing Power MOSFET resistance is greatly

* Dept. of Photovoltaic Engineering, Far East University

$\star$ Corresponding author : keg@kdu.ac.kr , Tel:+82-43-879-3590

Manuscript received Aug. 16, 2013; revised Sep. 15,2013 ; accepted Sep 16. 2013 lowered through the Super Junction structure compared with existing Planar MOSFET without any change of the voltage-driven loss, and will significantly reduce the resistance to the implementation and the decrease.[3-5]

\section{Experiment Method}

2.1 Theoretical Inquiry of Super Junction MOSFET

In the case of the Super Junction MOSFET in the off state, the depleted layer is formed in the vertical direction, unlike the Planar MOSFET which created depleted layers in both horizontal and vertical directions. As shown in Fig. 1, this is due to the existence of the P-Pillar area, which the reverse direction voltage connects the areas of P-Pillar and N-Drift, which obtains a large commissure. For optimizing the breakdown voltage, the areas of $\mathrm{P}$-Pillar and $\mathrm{N}$-Drift both need perfect depletion, and for this P-Pillar and N-Drift areas' discharge amount need to satisfy equation (1), which will develop balance. [1] 


$$
N_{\text {a.titat }} W_{P}=N_{\text {d.d+it }} W_{N}
$$

The Super Junction MOSFET that satisfies expression 1 makes horizontal field as shown in drawing 1 due to the two areas having the same charge which depletes $\mathrm{P}-\mathrm{Pilates}$ and $\mathrm{N}$-Drift areas.
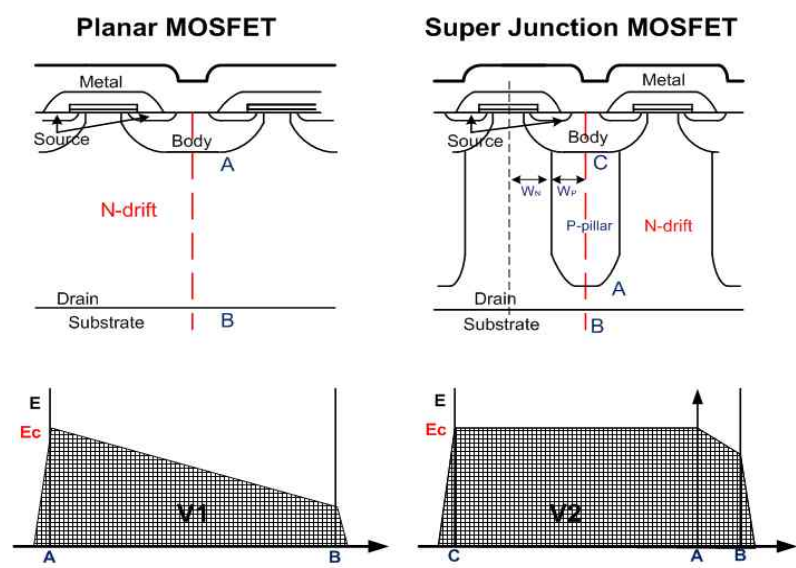

Fig. 1. The structures and electric fields of Planar and Super Junction Power MOSFET

\subsection{Basic Structure Design of Planar MOSFET}

The Planar MOSFET, which was used to compare to the Super junction of this thesis, is organized in table 1. The N-Drift's length was designed with the Super Junction MOSFET structure, for comparing the differences in temperature friction due to breakdown voltage, was set to $60 \mu \mathrm{m}$ and the optimal value of $600 \mathrm{~V}$ was drawn through changes in $\mathrm{N}$-Drift resistivity, $\mathrm{P}$-Base concentration.

Table 1. The design and process parameter $600 \mathrm{~V}$ Planar MOSFET

\begin{tabular}{lll}
\hline Parameter & Unit & Condition \\
\hline \hline N-drift (Resistivity) & $\Omega \mathrm{cm}^{3}$ & 18 \\
\hline JFET (Dose) & $\mathrm{cm}^{3}$ & $1 \mathrm{E} 12$ \\
\hline $\mathrm{P}-$ Base (Dose) & $\mathrm{cm}^{3}$ & $6.5 \mathrm{E} 13$ \\
\hline $\begin{array}{l}\text { N+ Substrate } \\
\text { (Resistivity) }\end{array}$ & $\Omega \mathrm{cm}^{3}$ & 0.018 \\
\hline $\mathrm{P}+$ (Dose) & $\mathrm{cm}^{3}$ & $3 \mathrm{E} 15$ \\
\hline $\mathrm{N}+$ (Dose) & $\mathrm{cm}^{3}$ & $5 \mathrm{E} 15$ \\
\hline Gate (Length) & $\mu \mathrm{m}$ & 4 \\
\hline
\end{tabular}

Table 2. The optimal electrical characteristics of $600 \mathrm{~V}$ Planar MOSFET

\begin{tabular}{lll}
\hline Vth & BV & Rds(on)@(100A/cm2) \\
\hline $3.7 \mathrm{~V}$ & $722 \mathrm{~V}$ & $0.15 \Omega \mathrm{cm} 2$ \\
\hline
\end{tabular}

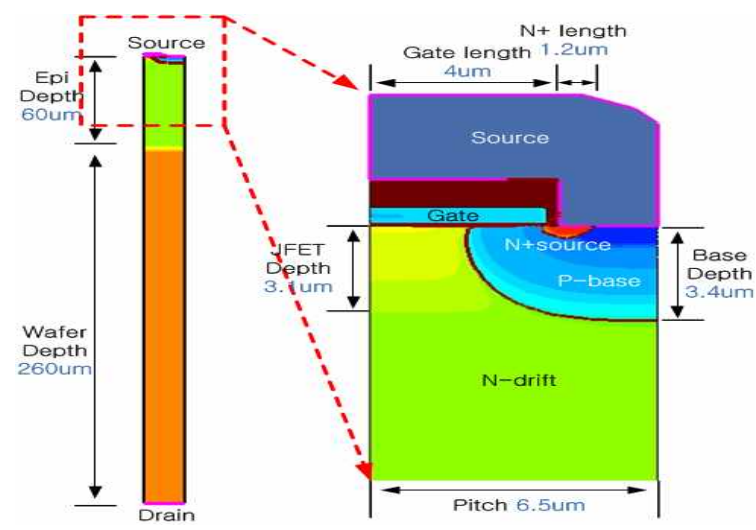

Fig. 2. $600 \mathrm{~V}$ Planar MOSFET Optimization Design

2.3 Basic Structure Design of Super Junction MOSFET

Optimized structure was proceeded by developing a structure from Super Junction MOSEFT to the 600 $\mathrm{V}$ Planar MOSFET from the top, and separate the areas of the N-Pillar(N-Drift), P-Pillar, while matching the charge balance. The developed results are in Table 3 and Fig 3.

Table 3. The design and process parameters of Super Junction MOSFET

\begin{tabular}{|c|c|c|}
\hline Parameter & Unit & Condition \\
\hline N-Drift (Resistivity) & $\Omega \propto \hat{t}^{2}$ & $18(2,49 \mathrm{E} 14)$ \\
\hline P-Pillar (Depth) & $\mu \mathrm{m}$ & 45 \\
\hline P-Pillar (Length) & $\mu \mathrm{m}$ & 3.25 \\
\hline Deep trench (Angle) & $0^{\circ}$ & 89.5 \\
\hline J-FET & $\mathrm{cit}$ & $1 \mathrm{E} 12$ \\
\hline P-Base & $d \hat{\imath}$ & $6,5 \mathrm{E} 13$ \\
\hline $\mathrm{N}+$ Substrate(Resistivity) & $\Omega \mathrm{st}^{2}$ & 0,018 \\
\hline $\mathrm{P}+(\mathrm{D} \circ \mathrm{s} \theta)$ & $\mathrm{cos}^{2}$ & $3 \mathrm{E} 15$ \\
\hline $\mathrm{N}+(\mathrm{Dos} \theta)$ & $d \hat{c}$ & $5 \mathrm{E} 15$ \\
\hline Gate (Length) & $\mu \mathrm{m}$ & 4 \\
\hline $\mathrm{N}+$ (Length) & $\mu \mathrm{m}$ & 1.2 \\
\hline P-Pillar (Depth) & $\mu \mathrm{m}$ & 45 \\
\hline P-Pillar (Length) & $\mu \mathrm{m}$ & 3,25 \\
\hline Deep trench (Angle) & ${ }^{\circ}$ & 89.5 \\
\hline
\end{tabular}




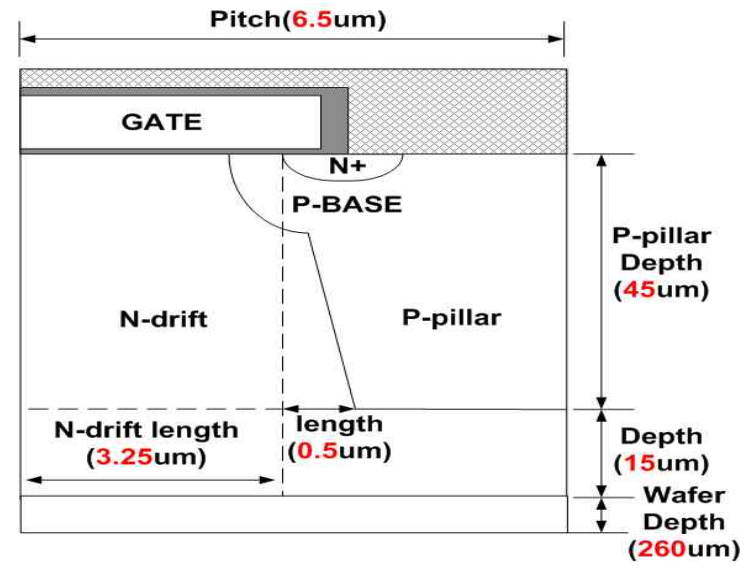

Fig. 3. The optimization structure of Super Junction MOSFET

To find out what happens to the breakdown voltage balance of the normal Super Junction MOSFET process condition when the P-Pillar and N-Drift concentrations are changed, the results were made of the simulation in Table 3 and Fig 4 .

Table 4. Breakdown voltage which forms the charge balance

\begin{tabular}{cccc}
\hline N-Drift & N-Drift (Dose) & P-Pillar (Dose) & BV \\
(Resistivity) & & & \\
\hline \hline $0,1 \Omega$ & $8,09 \mathrm{E} 16$ & $2,19 \mathrm{E} 15$ & $37 \mathrm{~V}$ \\
\hline$\sim$ & $\sim$ & & $\sim$ \\
\hline $0,9 \Omega$ & $5,54 \mathrm{E} 15$ & $6,54 \mathrm{E} 15$ & $680 \mathrm{~V}$ \\
\hline & & $5,44 \mathrm{E} 15$ & $730 \mathrm{~V}$ \\
\cline { 3 - 4 } $1,0 \Omega$ & $4,94 \mathrm{E} 15$ & $5,64 \mathrm{E} 15$ & $744 \mathrm{~V}$ \\
\cline { 3 - 4 } & & $5,84 \mathrm{E} 15$ & $727 \mathrm{~V}$ \\
\hline $1,5 \Omega$ & $3,22 \mathrm{E} 15$ & $3,71 \mathrm{E} 15$ & $817 \mathrm{~V}$ \\
\hline $2,0 \Omega$ & $2,37 \mathrm{E} 15$ & $2,55 \mathrm{E} 15$ & $844 \mathrm{~V}$ \\
\hline $2,5 \Omega$ & $1,88 \mathrm{E} 15$ & $2,24 \mathrm{E} 15$ & $876 \mathrm{~V}$ \\
\hline
\end{tabular}

As shown in the results of the simulation of changing the specific resistance of $\mathrm{N}$-Drift from 0.1 $\Omega$ to $2.5 \Omega$ in stages, shown in the fourth diagram, when the specific resistance increases, in order to achieve the charge balance, the breakdown voltage also rises in proportion to the specific resistance, and when the $\mathrm{N}$-Drift Concentration is 4.94E15, and the P-Pillar Concentration is 5.84E15; it was confirmed that it has the same breakdown voltage of 727V; same as that of Planar Power MOSFET

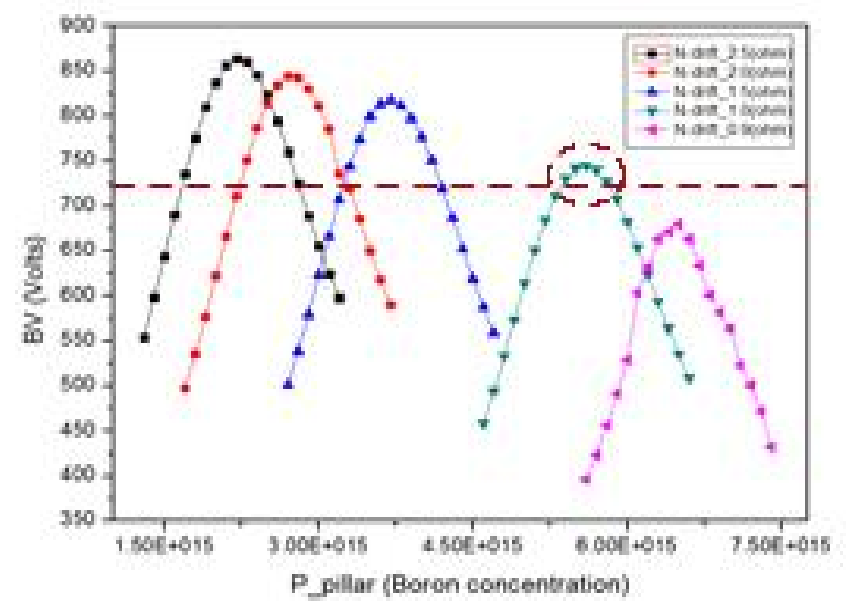

Fig. 4. The breakdown voltages according to P-pillar and $\mathrm{N}$-drift resistivity

Table. 5. 600 V Super Junction MOSFET Optimization Parameters

\begin{tabular}{|c|c|c|}
\hline Parameter & Unit & Condition \\
\hline N-drift (Resistivity) & $\Omega \omega \hat{t}$ & $1,0(4,94 \mathrm{E} 14)$ \\
\hline P-Pillar (Dos $)$ & $\mathrm{cs \hat {t }}$ & $5.84 \mathrm{E} 15$ \\
\hline P-Pillar (Depth) & $1 \mathrm{~m}$ & 45 \\
\hline P-Pillar (Length) & $10 \mathrm{~m}$ & 3,25 \\
\hline Deep trench (Angle) & 0 & 89.5 \\
\hline $\mathrm{J}-\mathrm{FET}$ & $c \hat{c}$ & $1 \mathrm{E} 12$ \\
\hline P-Base & $\mathrm{cs \hat {t }}$ & $6.5 \mathrm{E} 13$ \\
\hline $\mathrm{N}+$ Substrate (Resistivity) & $\Omega \omega \hat{t}$ & 0,018 \\
\hline $\mathrm{P}+(\mathrm{Dos} \theta)$ & $c \hat{c}^{2}$ & $3 \mathrm{E} 15$ \\
\hline $\mathrm{N}+(\mathrm{Dos} \theta)$ & $\mathrm{cs \hat {t }}$ & $5 \mathrm{E} 15$ \\
\hline Gate (Length) & $\mu \mathrm{m}$ & 4 \\
\hline $\mathrm{N}+$ (Length) & $10 \mathrm{~m}$ & 1.2 \\
\hline
\end{tabular}

Table 6. The optimization electrical characteristics of $600 \mathrm{~V}$ Super Junction MOSFET

\begin{tabular}{ccc}
\hline Vth & BV & Bds(on)@ $\left(100 \mathrm{~A} / \mathrm{cm}^{2}\right)$ \\
\hline \hline 4.7 & 727 & $0.019 \Omega \mathrm{cm}^{2}$ \\
\hline
\end{tabular}




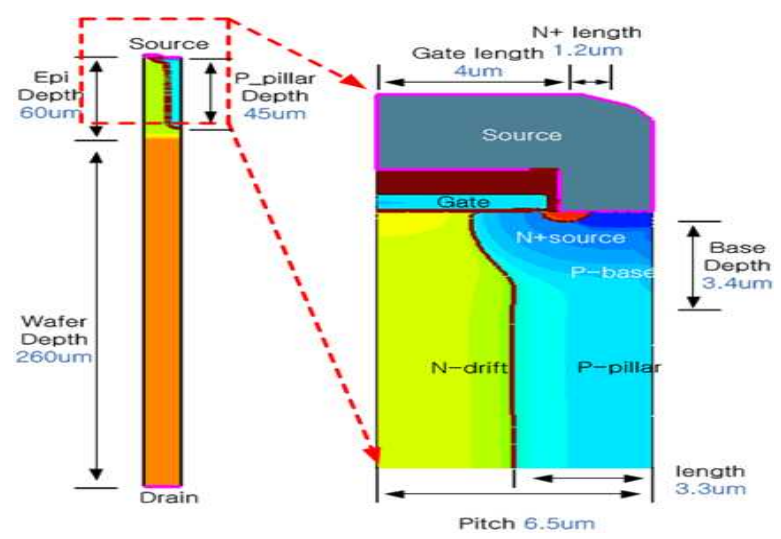

Fig. 5. 600 V Super Junction MOSFET Optimization Design
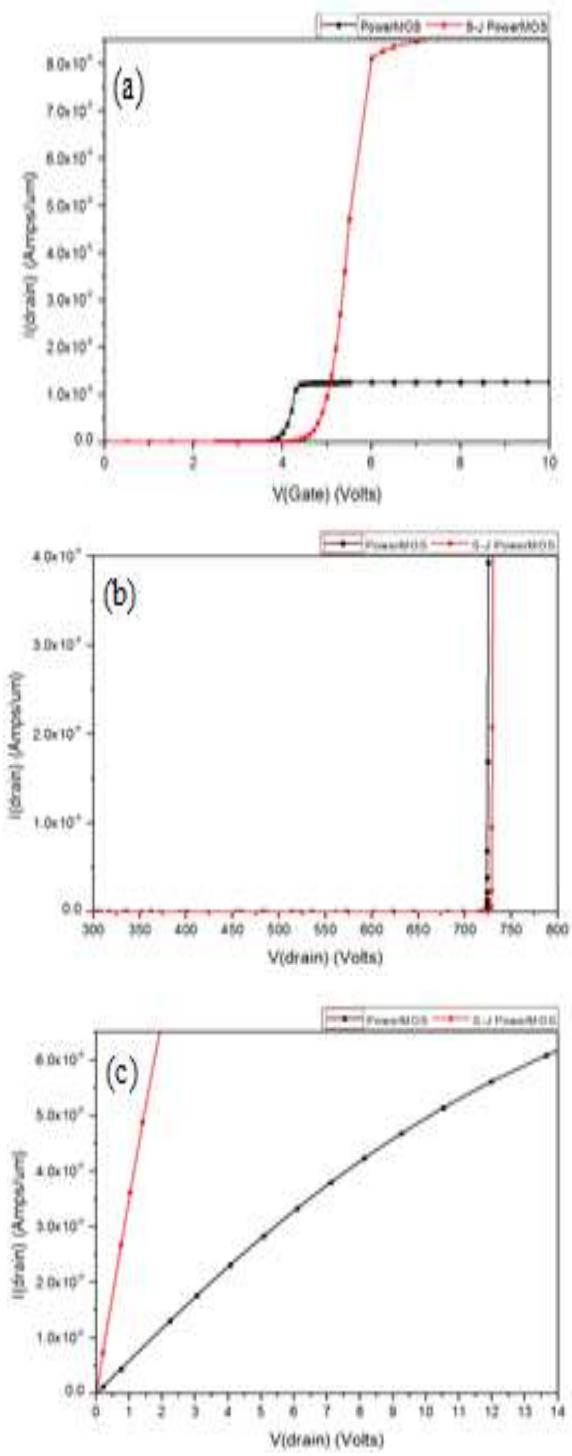

Fig. 6. Threshold voltage, breakdown voltage, on resistance optimization in respect of planar, Super Junction (a) Vth,(b)BV,(c)Ron.

\section{Results and Analysis}

The optimized characteristic comparison of Planar MOSFET and Super Junction MOSFET are shown in Fig. 6, and diagram 7. As shown in the diagram, with the same breakdown voltage, the temperature resistance of the Super Junction MOSFET became much lower.

Table 7. Threshold voltage, breakdown voltage, on resistance optimization in respect of planar, Super Junction

\begin{tabular}{cccc}
\hline & Vth & BV & Bdscon $) Q\left(100 \mathrm{~A} / \mathrm{cm}^{2}\right)$ \\
\hline \hline $\begin{array}{c}\text { Planar } \\
\text { MOSFET }\end{array}$ & 3.7 & 722 & $0.15 \Omega \mathrm{cm}^{2}$ \\
\hline $\begin{array}{c}\text { Super } \\
\text { Junction } \\
\text { MOSFET }\end{array}$ & 4.7 & 727 & $0.019 \Omega \mathrm{cm}^{2}$ \\
\hline
\end{tabular}

\section{Conclusion}

The maximum breakdown voltage's characteristic within the Super Junction MOSFET structure comes from N-Drift and P-Pillar's charge balance. By developing $\mathrm{P}-$ Pillar from Planar MOSFET, it was confirmed that the breakdown voltage is improved through charge balance, and by setting the gate voltage at $10 \mathrm{~V}$, the characteristic comparisons of Planar MOSFET and Super Junction MOSFET are shown in picture 6 . The results show that it had the same breakdown voltage as Planar MOSFET which increasing temperature resistance by $87.4 \%$ at $.019 \Omega \mathrm{cm}^{2}$ which shows that by the temperature resistance increasing, thepower module's power dissipation improved.

\section{References}

[1] Fujihira, T, Proc. of the ISPSD'98, Kyoto(1998), pp.423-426

[2] H. Ninomiya, Y.Miura and K Kobayashi, Proc. ISPSD(2004), pp.177-180

[3] Pravin N. Kondekar, TENCON Vol.4(2003), pp.1455-1458.

[4] S. Iwamoto, K. Takahashi, H. Kuribayashi, S. Wakimoto, K. Mochizuki and H. Nakazawa, Power 
Semiconductor Devices and Ics, Proceedings. ISPSD'05. The $17^{\text {th }}$ InternationalSymposiumon(2005), pp.31-34

[5] Yoshiyuki Hattori, Kyoko Nakashima, Makoto Kuwahara, Tomoyuki Yoshida, Shoichi Yamauchi and Hitoshi Yamaguchi, Proceedings of International symposium on Power Semiconductor Devices \& ICs, Kitakyushu(2004), pp.189-192

[6] E.G. Kang, S.H. Moon and M.Y. Sung, Microelectronics journal, Vol.32, Issue.8(2001), pp.641-647

[7] E.G. Kang and M.Y. Sung, Solid-State Electronics, Vol.46, Issue.2(2002), pp.295-300

[8] E.G. Kang, S.H. Moon, S.S. Kim and M.Y. Sung, Transactions on Electrical and Electronic Materials, Vol. 2, No.1(2001), pp.32-38

[9] E.G. Kang and M.Y Sung, Transactions on Electrical and Electronic Materials, Vol. 2, No.3(2001), pp.33-37

[10] J.S. Lee, H.H. Shin, H.S. Lee, E.G. Kang and M.Y. Sung, International conference on Power Electronics, (2007), pp.62-65

\section{BIOGRAPHY}

Ey Goo Kang (Life Member)

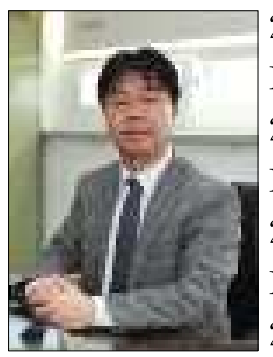
2000 : BS degree in Electrical Engineering, Korea University. 2005: MS degree in Electrical Engineering, Korea University. 2006 : PhD degree in Electrical Engineering, Korea University. 2003 present : professor in department of photo voltaic engineering, Far East University 